\title{
Overseeding Florida Lawns for Winter Color 1
}

\section{L.E. Trenholm and J. Bryan Unruh²}

In many parts of Florida, permanent lawngrasses go dormant in the late fall and early winter. This results in an unattractive brown lawn in which weeds can be easily seen.

A practice called overseeding is often used to provide green winter turf cover. In overseeding, a temporary cool-season grass is seeded into the permanent lawn. Grasses used for overseeding will die out in the spring, when the warm-season grass comes out of dormancy.

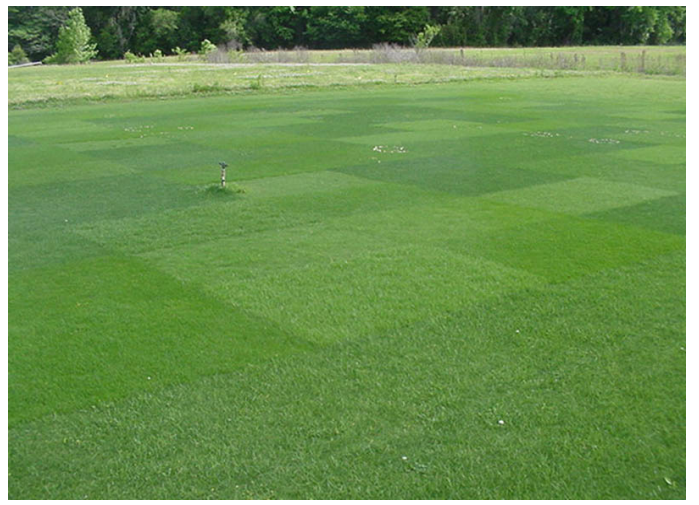

Figure 1. Overseeding provides green winter turf cover.

Overseeding is primarily used on golf courses, athletic fields, and high-profile landscape areas, but the principles can easily be applied by homeowners wishing to have year-round green lawns. It is important, however, to remember that this practice involves year-round lawn maintenance, including fertilization, irrigation, and mowing. Make sure you are ready for this increased maintenance if you decide to overseed.

\section{Which Grass to Use}

- Ryegrass is the best choice for overseeding home lawns.

- Ryegrasses (annual, intermediate, and improved/perennial) are popular because of:

- rapid seed germination

- fast growth

- adaptability

- reasonably low cost

- tolerance for sun or shade

- tolerance for close, frequent mowing

1. This document is ENH14, one of a series of the Environmental Horticulture Department, Florida Cooperative Extension Service, Institute of Food and Agricultural Sciences, University of Florida. Original publication date August 22, 2001. Revised November 2007. Visit the EDIS Web Site at http://edis.ifas.ufl.edu.

2. L.E. Trenholm, Associate Professor, Turfgrass Specialist, Department of Environmental Horticulture, Institute of Food and Agricultural Sciences, University of Florida, Gainesville, FL 32611,

J. Bryan Unruh, Associate Professor, West Florida Research and Education Center, Institute of Food and Agricultural Sciences.

The Institute of Food and Agricultural Sciences (IFAS) is an Equal Opportunity Institution authorized to provide research, educational information and other services only to individuals and institutions that function with non-discrimination with respect to race, creed, color, religion, age, disability, sex, sexual orientation, marital status, national origin, political opinions or affiliations. U.S. Department of Agriculture, Cooperative Extension Service, University of Florida, IFAS, Florida A. \& M. University Cooperative Extension Program, and Boards of County Commissioners Cooperating. Larry Arrington, Dean 
- Ryegrass, seeded heavily and mowed closely, can provide a dense and beautiful lawn throughout the winter.

- By the time the ryegrass dies, the permanent lawngrass should be actively growing again. It will provide color and cover for the rest of the growing season.

- The ryegrass will have to be reseeded each fall to provide a green wintertime lawn.

\section{Ryegrass for Winter Lawns}

\section{- Timing}

- It is best to wait until the daytime temperatures are consistently in the low- to mid-seventies, Fahrenheit.

- North Florida seeding time: October to early November.

- Central Florida seeding time: October to mid-November and early December.

- Water stress and diseases may reduce the chance of seedling survival if the seeds are planted during warmer periods.

- In frost-free areas of south Florida, lawns generally do not go dormant, and overseeding is probably not needed for winter color.

\section{Seedbed Preparation}

The two most important steps in overseeding are:

1. proper seedbed preparation

2. proper watering

\section{Seedbed Preparation}

To prepare the lawn for overseeding, rake the grass thoroughly to remove all debris. Next, mow the lawn closely. For St. Augustinegrass lawns, do not mow lower than 3 inches. Catch all clippings or rake the grass afterwards. The lawn may need to be cut more than once to reduce it to the desired height. The overseeded grass seed must contact the soil for optimum performance.

\section{Dethatching}

A lawn with heavy thatch produces an overseeded lawn with irregular patches. Dethatching with a power vertical mower or power rake (these can be rented) is advisable. For more information on thatch, please refer to ENH012, "Thatch and its Control in Your Florida Lawn".

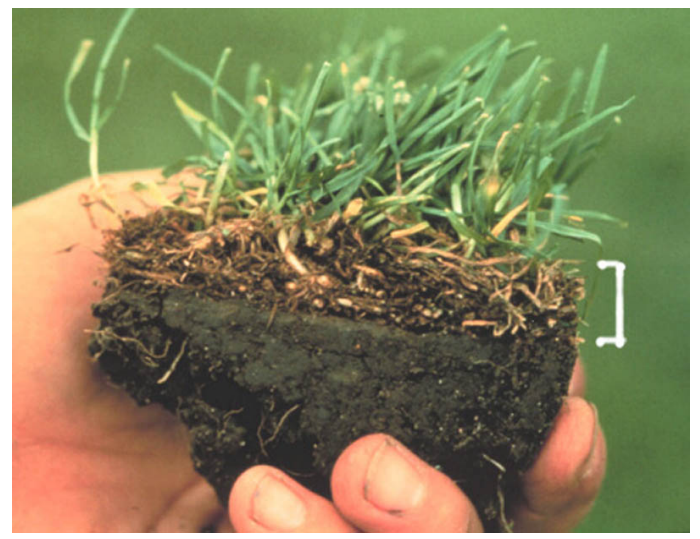

Figure 2. A heavy thatch can lead to a lawn with irregular patches.

Vertical mower blade spacing should be 3 inches for St. Augustinegrass and bahiagrass, 2 inches for centipedegrass and coarse-textured zoysiagrass, and 1 inch for bermudagrass and fine-textured zoysiagrass. A final raking will remove additional material and loosen the soil so the seed can come in contact with the soil.

\section{Seeding}

The next step is seeding. Rates listed in Table 1 will produce reasonably good color and density. If a heavy thatch layer exists, increase seeding rates 25 $50 \%$. If available, buy fungicide-treated seed.

For best coverage, use a mechanical seeder. Sow half the seed as you walk in one direction, and the other half by walking at right angles to the first. A very uniform stand can be established this way. After seeding, rake the ground with a stiff broom to ensure the seed gets through the grass and is in contact with the soil. 
Table 1. Overseeding Rates for Homelawns

\begin{tabular}{|l|l|}
\hline \hline $\begin{array}{l}\text { Overseed } \\
\text { Grass }\end{array}$ & $\begin{array}{l}\text { Seeding rate } \\
\text { in lbs/1000 sq. ft. }\end{array}$ \\
\hline Bluegrass & 3 \\
Fescue & 7 \\
$\begin{array}{l}\text { Ryegrass } \\
\text { (annual) }\end{array}$ & 10 \\
$\begin{array}{l}\text { Ryegrass } \\
\text { (intermediate) } \\
\begin{array}{l}\text { Ryegrass } \\
\text { (perennial) }\end{array}\end{array}$ & 10 \\
\hline \hline
\end{tabular}

\section{Watering}

Watering is the last but most important step in establishing the winter lawn.

Water should be applied lightly and carefully to the seeded lawn once or twice a day until the seeds have germinated (7 - 10 days). Daily watering should continue for 2 - 3 weeks, until seedlings are well established. Do not overwater when you irrigate. Overwatering will wash seed away and encourage disease development. Once the plants are well established (e.g., mowed several times), water as needed to prevent wilting.

\section{Maintenance of Winter Lawn}

Once the winter lawn is established, it will require the same maintenance as the permanent lawn. This includes mowing, watering, fertilizing, and controlling pests.

- Mowing should begin when the overseeded grass is tall enough to be cut (around 1 - 2 inches above the permanent grass). Properly fertilized ryegrass grows very quickly, so weekly mowing will probably be required. Do not mow with a dull blade - the seedlings may be torn from the ground or have a ragged appearance.

- Water as needed to keep the grass from wilting.

- Fertilize to keep the ryegrass growing vigorously and to maintain a deep green color. To help prevent root burn, the first application should follow the second mowing. For the first application, apply a lawn fertilizer at the recommended rate. For more information on fertilizing, please refer to ENH962, "Figuring
Out Fertilizer for the Home Lawn." Apply fertilizer again approximately 60 days after Application 1.

Ryegrass is very susceptible to a disease called pythium. For more information, please refer to EDIS publication PP203, "Pythium Blight of Overseeded Turfgrasses."The disease appears most severely on overwatered, overfertilized ryegrass, especially during warm, humid weather. Using fungicide-treated seed, along with cultural practices such as seeding during the coolest months, proper watering and fertilizing, and appropriate fungicide applications, may help prevent the disease.

If Pythium occurs, a fungicide should be applied immediately, because this disease can kill the entire winter lawn in 24 - 48 hours. For chemical disease control recommendations, please refer to EDIS publications SS-PLP-11, "Pythium Root Rot" and SS-PLP-14, "Turfgrass Disease Management."

\section{Reestablishing Permanent Grass}

To maintain good vigor in the permanent lawngrass, do not encourage the winter grass to continue growing as temperatures rise in the spring. The permanent lawngrass can be weakened by the highly competitive ryegrass during this overlapping season of growth. Ryegrass will normally die out in late spring, but if the weather is cool and the lawn is watered frequently, it can be very persistent.

To discourage the ryegrass, discontinue fertilization in February (south Florida) and March (north Florida). Water as infrequently as possible, making sure the permanent lawngrass does not suffer excessively. Continue to mow the ryegrass as closely as possible each week. These practices tend to weaken the winter grass and facilitate a faster transition back to the permanent lawngrass. Once the permanent lawngrass has resumed growth, begin your regular lawn maintenance program. 